\section{Case of spontaneous haemothorax associated with an endodermal sinus tumour}

\author{
Metin Karaböcüoḡlu, Serpil Uḡur, \\ Nedret Uzel, Enver Dayioğlu, \\ Dilek Yilmazbayhan, Ridvan Ilhan
}

\begin{abstract}
Spontaneous haemothorax is rare in infants. A case is reported of a nine month old infant who was found to have an endodermal sinus tumour.
\end{abstract}

Institute of Child

Health

M Karaböcüoḡlu

$S$ Ūgur

N Uzel

Department of

Cardiothoracic

Surgery

E Dayioḡu

Department of

Pathology

D Yilmazbayhan

$R$ İlhan

Istanbul Faculty of Medicine, University of Istanbul, Turkey

Reprint requests to:

Dr M Karaböcüoḡlu, I.U.

Capa Cocuk Hastanesi,

Capa-Topkapi, Istanbul

34390, Turkey

Received 13 August 1992 Returned to authors 22 October 1992

Revised version received

11 December 1992

Accepted 24 December 1992 the pleural fluid did not reveal any malignant cells or bacteria. A thoracic computed tomographic scan showed a small pneumothorax on the right side and atelectasis in the basal segments of the right lower lobe. The patient improved, but on the 15th day of admission dyspnoea and cyanosis suddenly developed. Chest radiography showed complete opacification of the right hemithorax and $280 \mathrm{ml}$ of bloody fluid was drained and a thoracotomy performed. At exploration a haematoma within the anterior wall of the thorax and a necrotic, haemorrhagic tumour $(5 \times 4 \times 4$ $\mathrm{cm}$ in size) was detected. This mass was adherent to the right lateral thoracic wall and a metastasis was found on the right lobe of the liver. No tumour was found in the mediastinum. The neoplasm was excised by right lower lobectomy. On macroscopic examination the right lower lobe was $6 \times 6 \times 4 \mathrm{~cm}$ in size and the visceral pleura thickened. Firm, gray-yellow irregular pieces of tumour tissue were seen. The biggest was $4 \times 2 \times$ $1.5 \mathrm{~cm}$ in size and some were haemorrhagic.

Microscopic examination showed atelectatic and interstitial fibrotic changes in the lung tissue. There was some compensatory emphysema within the lobe. Fibrous thickening and some haemorrhagic areas were seen in the pleural tissues. The tumour comprised a loose, vacuolated network with small cystic spaces forming a honeycomb pattern (fig 1). Numerous round hyaline globules were present inside and outside the cells (PAS positive) (fig 2) with perivascular formation (Shiller-Duvel bodies) and, in some areas, alveolar gland formation was seen. It was diagnosed as an "endodermal sinus tumour" and thought to be a metastasis originating from a primary tumour in the mediastinum. No other component was found to suggest that it was a teratoma. Computed tomographic scans of the brain, mediastinum, abdomen, and pelvis, and ultrasonography of the gonads showed no other foci. Laboratory test results showed increased plasma levels of $a$-fetoprotein (660 milliunits $/ \mathrm{ml}$ ) and carcinoembryonic antigen $(18 \mathrm{ng} / \mathrm{ml})$. The level of $\beta$-human chorionic gonadotrophin was nor$\mathrm{mal}$ ( $1 \mathrm{milliunit} / \mathrm{ml})$. Chemotherapy was initiated and eight months later the patient was still in remission and $a$-fetoprotein levels had returned to normal.

\section{Discussion}

Spontaneous haemothorax is rarely seen in childhood. Neoplasms are among the rare causes of spontaneous haemothorax. In our patient the diagnosis of an endodermal sinus tumour was made at thoracotomy because of recurrent haemothorax. In 1988 Templeton et al first reported an extragonadal germ cell tumour in an adult who presented with a spontaneous haemothorax simulating an aortic dissection. ${ }^{1}$ Klotti and colleagues reported a child with malignant thoracic teratoma who had presented with a spontaneous haemothorax. $^{2}$
Figure 1 Loose vacuolated network, with small cystic spaces. Stain: haematoxylin and eosin. Original magnification $\times 125$. 


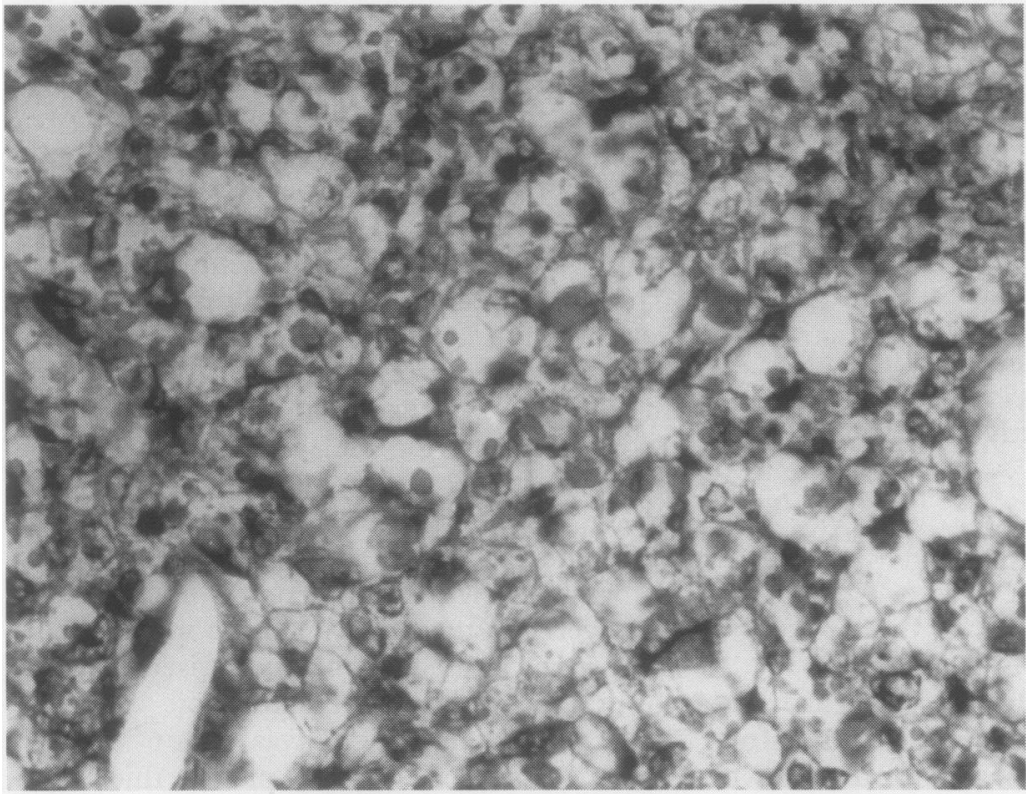

Figure 2 A loose vacuolated network of tumour tissue with hyaline globules both inside and outside the cells. Stain: haematoxylin and eosin. Original magnification $\times 500$.

Endodermal sinus tumours are the most common malignant germ cell neoplasm seen in childhood. They usually originate from the gonads, ${ }^{3}$ but on rare occasions they may be seen in the retroperitoneum, anterior mediastinum, pleura, pericardium, sacrococcyx, central nervous system, liver, and vagina. ${ }^{34}$ The discovery of the metastasis to the peritoneum, pericardium, lymph nodes, and the lungs may be the first manifestation of the tumour. ${ }^{4}$ In our patient there was no evidence of any other lesion.

Despite the fact that malignant tumours are rare causes of spontaneous haemothorax they must not be overlooked in the differential diagnosis. In cases of haemothorax of unknown aetiology thoracotomy may be indicated.

1 Templeton PA, Vanright JR, Rodriquez A, Diaconis JN. Mediastinal tumours presenting as spontaneous haemathorax, simulating aortic dissection. Chest 1988;93:828-30.

2 Klotti J, Walliser G, Sacher P. Nontrauma-induced haemothorax a certain leading symptom of a malignan tumour. $Z$ Kinderchir 1989;44:115-8.

3 Kuzur ME, Cobleigh MA, Greco FA, Einhorn LH, Oldham RK. Endodermal sinus tumour of the mediastinum. Cancer 1982;50:766-74.

4 Truong LD, Harris L, Mattioli C, Hawkins E, Lee A. Endodermal sinus tumour of the mediastinum. Cancer 1986;58:730-9.

\section{Catamenial haemoptysis: a rare} cause

D J Wood, K Krishnan, P Stocks, E Morgan, M J Ward

\footnotetext{
Department of

Medicine

D J Wood

K Krishnan

M J Ward

Department of

Histopathology

P Stocks

Kings Mill Hospital

Mansfield Road,

Sutton in Ashfield

NG17 4JL

Department of

Thoracic Surgery,

City Hospital,

Nottingham NG5 1PB

E Morgan

Reprint requests to:

Dr M J Ward

Received 30 April 1992

Returned to authors

8 June 1992

Revised version received

18 November 1992

Accepted 8 December 1992
}

\begin{abstract}
Since the first report of pulmonary endometriosis as a cause of catamenial haemoptysis all cases have been assumed to be due to pulmonary endometriosis, even in the absence of histopathological proof. A case is presented where the histological findings were of a pulmonary arteriovenous malformation.
\end{abstract}

(Thorax 1993;48:1048-1049)

Periodical haemoptysis occurring in association with the menses (catamenial haemoptysis) is a rare entity. Since the first published case, which was due to endometriosis of the lung, ${ }^{1}$ there have been fewer than 20 reported cases. All the cases described have been attributed to pulmonary endometriosis although less than one third have had histological evidence.

\section{Case report}

A 32 year old woman presented with a 10 month history of recurrent haemoptysis occurring during every menstrual cycle. Symptoms started on the second day of her menses and lasted for three days. The haemoptysis was associated with mild right sided pleuritic type chest pain and never occurred without a period. No other symptoms were noted.

Two years previously she had been treated with methotrexate for nine months for an invasive hydatidiform mole. She had had normal menstruation and serum gonadotrophin levels ever since chemotherapy.

Clinical examination was normal Laboratory investigations revealed normal full blood count, erythrocyte sedimentation rate, urea and electrolyte levels, liver function tests, bone profiles, coagulation studies, and serum gonadotrophin levels. Chest radiography during haemoptysis was normal but fibreoptic bronchoscopy revealed blood originating from the posterior segment of the right upper lobe but no endobronchial lesion was seen. Computed tomography during haemoptysis revealed a fairly well demarcated area of patchy consolidation posteriorly in the right upper lobe. Computed tomography was repeated in the middle of the cycle and revealed a small subpleural nodule at the same site with no evidence of surrounding consolidation or haemorrhage.

The patient was treated by posterior seg- 